DOI: http://dx.doi.org/10.33846/hn31001

http://heanoti.com/index.php/hn

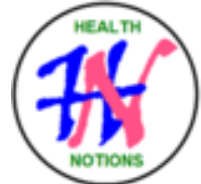

RESEARCH ARTICLE

URL of this article: http://heanoti.com/index.php/hn/article/view/hn31001

\title{
Clinical Features in Metastatic Bone Disease with and without Pathological Fractures: A Comparative Study
}

Putu Garry $^{1(\mathrm{CA})}$, Mouli Edward ${ }^{2}$, Rosy Setiawati ${ }^{3}$, Sjahjenny Mustokoweni $^{4}$, Ferdiansyah Mahyudin $^{5}$

${ }^{1(\mathrm{CA})}$ Faculty of Medicine, Airlangga University, Indonesia; 9egarry10@ gmail.com (Corresponding Author)

${ }^{2}$ Orthopaedic and Traumatology Department, Dr. Soetomo General Academic Hospital, Indonesia; medortho@gmail.com

${ }^{3}$ Radiology Department, Dr. Soetomo General Academic Hospital, Indonesia; dr_setia76@yahoo.co.id ${ }^{4}$ Pathology Anatomy Department, Dr. Soetomo General Academic Hospital, Indonesia; sjahjenny@ gmail.com ${ }^{5}$ Orthopaedic and Traumatology Department, Dr. Soetomo General Academic Hospital, Indonesia; ferdyortho@yahoo.com

\begin{abstract}
Background: Pathological fracture complications such as impaired clinical features is suspected to increase the mortality in MBD. In Indonesia, the habit of delayed seeking of medical treatment was common and potentially led to pathological fracture. Aim: This study compared the clinical features between MBD with and without pathological fracture. Methods: This was a retrospective study of MBD at Dr. Soetomo General Hospital in 2011-2015. We compared the clinical features by pain in Visual Analog Scale (VAS); general health presentation represented by laboratory findings; and the history of non-medical treatments. Results: 64 patients had MBD were included in this study. 37 (57.8\%) of them presented with pathological fractures, and 27 (42.2\%) without. Pain was the most common chief complaint $(76.5 \%)$. No significant difference found between the MBD with and without pathological fracture in all variables $(\mathrm{p}=0.122 ; \mathrm{p}=0.64 ; \mathrm{p}=0.823 ; \mathrm{p}=0.417, \mathrm{p}=1.000$ for VAS, hemoglobin, albumin, calcium, and history of non-medical treatment respectively). This probably associated with the therapy and a variety of primary tumors underlying the MBD. However, 6 out of 10 patients with history non-medical treatment presented with fractures. Conclusion: There's no significant difference in clinical features of MBD from both groups, while those with fractures had worse conditions.
\end{abstract}

Keywords: Metastatic bone disease, Pathological fracture, Clinical features

\section{INTRODUCTION}

\section{Background}

The development of treatment in cancer, which prolongs the patient's life, increases the prevalence of bone metastasis cases ${ }^{(1)}$. Metastatic bone disease (MBD) is an important factor of morbidity due to the limited range of motion (ROM) and pathological fractures accompanied by pain ${ }^{(2)}$. Median survival rates of cancer patients with MBD range from 21-33 months after a diagnosis of bone metastasis was made. Furthermore, MBD also causes pathological fractures. The increased risk of death due to pathological fractures in various cancer patients is suspected regarding to associated complications such as: (1) surgery for pathological fractures, (2) loss of mobility and functionality, (3) complications of increased risk of deep vein thrombosis (DVT), and (4) impaired clinical conditions that may occur ${ }^{(3)}$. Morbidity and an increased risk of mortality that is posed by pathological fractures resulting from MBD can be worsened by late medical treatment. As in Indonesia, due to various reasons such as financial issues, belief in conventional medicine, less health information received, and personal and other people's experiences, people prefer traditional medicine rather than modern medicine ${ }^{(4)}$. The 
problem of Indonesian people's habit in delayed seeking of medical help for their illness is the main reason we conduct this study. This study aimed to compare clinical features between MBD patients with and without pathological fractures admitted to the hospital. Clinical features used as comparison instruments in MBD patients with and without pathological fractures were pain severity, which was measured using Visual Analog Scale (VAS); the patient's general health presentation, represented by laboratory findings such as hemoglobin, albumin, and calcium level; and a history of non-medical treatment before hospital admission, which can delay patients from getting medical treatment.

\section{Purpose}

This study compared the clinical features between MBD patients with pathological fractures and without pathological fractures.

\section{METHODS}

This was a retrospective study of metastatic bone diseases at the Orthopaedic and Traumatology Department, Dr. Soetomo General Hospital Surabaya, Indonesia. All patients who were diagnosed with MBD in January 2011-December 2015 were included in the present study. The data were obtained from Dr. Soeotmo General Hospital's medical records unit. This study compared the clinical features between MBD with pathological fractures and without pathological fractures. Patients with primary bone tumors and incomplete MBD medical records were excluded. Data collected were patients demographics (gender and age) and clinical data (chief complaint, VAS, laboratory exams, primary malignancy, metastases sites, and pathological fracture status). Clinical features compared were VAS, laboratory findings such as hemoglobin, calcium, and albumin, which represented general health presentation and history of non-medical treatments. Data then analyzed statistically using the IBM Statistical Package for the Social Sciences, version 23. This study was approved by the Research Ethics Committee of Dr. Soetomo General Academic Hospital.

\section{RESULTS}

101 patients were diagnosed with bone tumors and referred to the Orthopaedic and Traumatology Department of Dr. Soetomo General Hospital. 79 of them were MBD and only 64 of them had complete medical records and included in this study. Of the $64 \mathrm{MBD}, 37$ (57.8\%) presented with pathological fractures and 27 $(42.2 \%)$ were without pathological fracture.

Table 1. Characteristics of MBD patients in Dr. Soetomo General Hospital in 2011-2015

\begin{tabular}{ccc}
\hline Characteristics & $\begin{array}{c}\text { Pathological } \\
\text { fracture }\end{array}$ & $\begin{array}{c}\text { Non-pathological } \\
\text { fracture }\end{array}$ \\
\hline Age & & \\
\hline $0-9$ & 0 & 2 \\
$10-19$ & 0 & 1 \\
$20-29$ & 3 & 1 \\
$30-39$ & 2 & 3 \\
$40-49$ & 3 & 4 \\
$50-59$ & 18 & 11 \\
$60-69$ & 8 & 2 \\
$70-79$ & 3 & 3 \\
\hline Sex & & \\
\hline Male & 15 & 12 \\
\hline Female & 22 & \\
\hline
\end{tabular}




\begin{tabular}{|c|c|c|}
\hline Characteristics & $\begin{array}{l}\text { Pathological } \\
\text { fracture }\end{array}$ & $\begin{array}{c}\text { Non-pathological } \\
\text { fracture }\end{array}$ \\
\hline \multicolumn{3}{|l|}{ Primary tumor } \\
\hline Breast & 12 & 4 \\
\hline Prostate & 2 & 2 \\
\hline Lungs & 3 & 4 \\
\hline Thyroid & 3 & 6 \\
\hline Skin & 1 & 0 \\
\hline Liver & 1 & 0 \\
\hline Lymphoma & 2 & 3 \\
\hline Nasopharynx & 0 & 1 \\
\hline Renal cancer & 1 & 2 \\
\hline Rectal cancer & 1 & 0 \\
\hline Ovarium & 1 & 0 \\
\hline Bladder cancer & 0 & 1 \\
\hline Larynx & 0 & 1 \\
\hline Cervix & 2 & 0 \\
\hline Others & 7 & 3 \\
\hline Unknown & 1 & 0 \\
\hline \multicolumn{3}{|l|}{ Metastases sites } \\
\hline Femur & 24 & 5 \\
\hline Spine & 11 & 9 \\
\hline Pelvis & 2 & 6 \\
\hline Humerus & 7 & 4 \\
\hline Tibia & 2 & 2 \\
\hline Ulna & 1 & 0 \\
\hline Others & 1 & 2 \\
\hline \multicolumn{3}{|l|}{ Chief complaint } \\
\hline Pain & 29 & 20 \\
\hline Lump & 7 & 10 \\
\hline Walking problems & 8 & 7 \\
\hline Extremity weakness & 3 & 3 \\
\hline
\end{tabular}

The majority of MBD patients who were referred to Dr. Soetomo were in the age group of above 50 years old (70.3\%) with the highest incidence of MBD occurred in patients aged of 50-59 years.

Table 2. Characteristics of MBD patients by age

\begin{tabular}{ccc}
\hline Age (years) & Pathological fracture & Non-pathological fracture \\
\hline Male & 15 & 15 \\
\hline $0-29$ & 3 & 3 \\
$30-49$ & 2 & 2 \\
$\geq 50$ & 10 & 10 \\
\hline Female & 22 & 12 \\
\hline $0-29$ & 0 & 1 \\
$30-49$ & 3 & 5 \\
$\geq 50$ & 19 & 6 \\
\hline
\end{tabular}


The primary tumors that were most involved in MBD were breast (24.6\%), thyroid (14.1\%), lung $(10.9 \%)$, and lymphoma (7.8\%). There were $17.2 \%$ of MBD patients whose primary tumors were not documented specifically, with the majority type of primary tumors are adenocarcinoma (27.3\%), squamous cell carcinoma, clear cell carcinoma and other types of malignancies.

Table 3. Characteristics of MBD patients by chief complaints and primary tumor

\begin{tabular}{ccccc}
\hline & & \multicolumn{3}{c}{ Chief complaint(s) } \\
& & (Pathological fracture: non-pathological fracture) \\
\hline Primary tumor & Pain & Lumps & Walking problems & Extremity weakness \\
\hline Breast & $9 ; 3$ & $1 ; 1$ & $2 ; 0$ & $1 ; 1$ \\
Prostate & $2 ; 1$ & $0 ; 0$ & $0 ; 1$ & $0 ; 0$ \\
Lung & $3 ; 4$ & $0 ; 1$ & $2 ; 1$ & $0 ; 1$ \\
Thyroid & $1 ; 4$ & $2 ; 3$ & $0 ; 3$ & $1 ; 0$ \\
Lymphoma & $2 ; 0$ & $1 ; 3$ & $1 ; 1$ & $0 ; 0$ \\
Renal & $0 ; 2$ & $1 ; 1$ & $0 ; 1$ & $0 ; 0$ \\
Cervix & $1 ; 0$ & $0 ; 0$ & $1 ; 0$ & $0 ; 0$ \\
Others & $8 ; 6$ & $2 ; 1$ & $2 ; 0$ & $0 ; 1$ \\
\hline
\end{tabular}

Most locations of MBD presented in metastases were femur (45.3\%), followed by spine (31.25\%), humerus $(17.1 \%)$, and pelvis (12.5\%). In the present study, $82.7 \%$ of MBD in the femur had pathological fractures. Pain was the most common chief complaint, experienced by 49 out of 64 patients (76.5\%), followed by lumps and walking problems. After the data were processed with statistical test, we concluded that there were no significant differences in clinical conditions between MBD patients with pathological fractures and without pathological fracture of all variables.

Table 4. Characteristics of MBD patients by metastases sites and gender

\begin{tabular}{ccc}
\hline Metastates sites & Pathological fracture & Non-pathological fracture \\
\hline Male & 11 & 3 \\
\hline Femur & 5 & 6 \\
Spine & 1 & 2 \\
Pelvis & 1 & 2 \\
Humerus & 1 & 4 \\
Others & & \\
Female & 13 & 2 \\
Femur & 6 & 3 \\
Spine & 1 & 4 \\
Pelvis & 6 & 2 \\
Humerus & 2 & 3 \\
Others & &
\end{tabular}

The 55 medical record datas included pain scales experienced by patients as measured by the VAS scale out of 64 patients. Of the 55 samples, we classified the VAS data of MBD patients into the following categories: mild for VAS scores of 1-3; moderate for VAS scores of 4-6; and severe for VAS scores of 7-10. A comparative test was then carried out and no statistically significant difference was found. The lowest and highest VAS 
values in pathological fractures group were 2 and 6 respectively, whereas in the group without pathological fracture, the lowest and highest VAS values were 2 and 8, respectively.

Table 5. Comparison of Pain Scale

\begin{tabular}{ccc}
\hline & Pathological fracture & $\begin{array}{c}\text { Non-pathological } \\
\text { fracture }\end{array}$ \\
\hline $\begin{array}{c}\text { Mild } \\
\text { (VAS 1-3) }\end{array}$ & $27 \%(\mathrm{n}=10)$ & $18.5 \%(\mathrm{n}=5)$ \\
$\begin{array}{c}\text { Moderate } \\
\text { (VAS 4-6) } \\
\text { Severe } \\
\text { (VAS 7-10) } \\
\text { No data }\end{array}$ & $67.6 \%(\mathrm{n}=25)$ & $37 \%(\mathrm{n}=10)$ \\
\hline
\end{tabular}

In terms of general health presentation, as measured by hemoglobin, calcium, and albumin levels, albumin and hemoglobin levels were found to be higher in MBD with pathological fractures than in MBD without pathological fracture. Meanwhile, calcium levels in pathological fractures were found to be lower in this study. However, the difference was not statistically significant.

Table 6. Comparison of General Body Conditions

\begin{tabular}{cccc}
\hline & Pathological fracture & $\begin{array}{c}\text { Non-pathological } \\
\text { fracture }\end{array}$ & P-value \\
\hline $\begin{array}{c}\text { Hemoglobin } \\
(\mathrm{n}=58)\end{array}$ & $11.82 \pm 1.64$ & $12.01 \pm 1.39$ & 0.640 \\
$\begin{array}{c}\text { Albumin } \\
(\mathrm{n}=22)\end{array}$ & $3.91 \pm 0.55$ & $3.86 \pm 0.4$ & 0.823 \\
Calcium $(\mathrm{n}=47)$ & $9.16 \pm 0.85$ & $9.24 \pm 0.86$ & 0.417 \\
\hline
\end{tabular}

The hemoglobin levels ranged from 9.5-15gr/dL in groups with pathological fractures and 9.9-16.4 g/dL in those without pathological fracture. Albumin levels ranged from 2.9-4.7 g/dL in pathological fractures group compared to 3.4-4.3 g/dL in without pathological fracture group. The percentage of patients with hypoalbuminemia in the group with and without pathological fractures were $42.8 \%$ and $50 \%$, respectively. In the group with pathological fractures, calcium levels ranged from 7.6 to $12.6 \mathrm{mg} / \mathrm{dL}$, whereas in the non-fracture group, the calcium level ranged from 7.5 to $11.3 \mathrm{mg} / \mathrm{dL}$.

In terms of non-medical treatment, there was no statistically significant difference between the group with pathological fractures and without pathological fracture. In this study, only 12 out of 64 (18.75\%) samples whose non-medical treatment history were known. Of the 10 samples with a history of non-medical treatment, 6 $(60 \%)$ had pathological fractures.

Table 7. Comparison of non-medical treatment history

\begin{tabular}{ccc}
\hline & $\begin{array}{c}\text { History of } \\
\text { non-medical treatment } \\
(+)\end{array}$ & $\begin{array}{c}\text { History of } \\
\text { non-medical } \\
\text { treatment }(-)\end{array}$ \\
\hline $\begin{array}{c}\text { Pathological } \\
\text { fracture }\end{array}$ & $6(85.7 \%)$ & $1(14.3 \%)$ \\
\hline $\begin{array}{c}\text { Non-pathological } \\
\text { fracture }\end{array}$ & $4(80 \%)$ & $1(20 \%)$ \\
\hline Total & $10(83.3 \%)$ & $2(18.7)$ \\
\hline
\end{tabular}




\section{DISCUSSION}

From 64 data samples in the form of MBD patients in Dr. Soetomo General Hospital in 2011-2015, 37 patients $(57.8 \%)$ were admitted with pathological fractures and $27(42.2 \%)$ were without. This is lower than the study conducted by Singh, Hasseb, and Alkubaisi at the University of Malaya Medical Center, where 106 out of 151 patients $(70.2 \%)$ had MBD with pathological fractures ${ }^{(5)}$. Another study showed that about 9-29\% of MBD patients experienced pathological fractures ${ }^{(6)}$. This difference could be associated with the underlying primary malignancies, where $60 \%$ of MBD with pathological fracture is caused by breast cancer (BC) and another $10 \%$ by lung cancer. $\mathrm{BC}$ is likely to cause pathological fractures, as most of the metastases are osteolytic which damages the bone and is mediated by osteoclasts ${ }^{(2)}$. Osteolytic types can be found with osteoblastic, nevertheless, osteolytic types are far more common and are related to skeletal-related events (SREs), including pathological fractures ${ }^{(7)}$. Most MBD patients involved were in the age group of above 50 years $(70.3 \%)$, in line with studies conducted by Singh et al., which showed $77 \%{ }^{(5,8)}$. BC was the most common tumor involved in MBD in this study $(24.6 \%)$, followed by thyroid (14.1\%), lung $(10.9 \%)$ and lymphoma (7.8\%). There were $17.2 \%$ of MBD patients with unknown primary tumor site, with the majority type of primary tumors was adenocarcinoma $(27.3 \%)$. MBD with an unknown site of origin can be found in about $10-15 \%$ of $\operatorname{cases}^{(9)}$.

After the data were processed with statistical tests, we conclude that there were no significant differences in clinical features between the pathological fractures group and without pathological fracture MBD while Saad et al., stated that pathological fracture could increase the risk of death through its complications ${ }^{(3)}$. Similar results also obtained in studies of osteosarcoma with pathological fractures, where the incidence of fracture was not proven to decrease the survival rate ${ }^{(10)}$. The results of a cohort study conducted by Singh et al., also showed that the incidence of pathological fractures did not significantly affect the condition of MBD patients ${ }^{(5)}$. However, the insignificant difference in this study could be due to the primary malignancies, where the clinical condition and symptoms also differed based on the accompanying primary malignancy ${ }^{(11)}$. Type of primary tumor also determine the survival rate, as in MBD patients with prostate cancer and $\mathrm{BC}$ can last for several years, whereas MBD from lung cancer lasts shorter ${ }^{(5)}$. The occurrence of metastases to other vital organs was found to worsen the prognosis of MBD patients, such as in breast and prostate cancer ${ }^{(12)}$. Therapy or treatment that had been given on MBD patients also affect the clinical condition. Interventions in the form of surgery to prevent pathological fracture in MBD patients produce better general conditions compared to MBD patients with pathological fracture that have already occurred ${ }^{(13)}$.

The incidence of pathological fractures did not make a significant difference. However, the clinical features of two study groups were found to be equally bad in terms of pain, which is showed by the large number of patients who came to the hospital with pain complaints $(76.5 \%)$, from both with and without fracture group. Pain increases morbidity and decreases the quality of life $(\mathrm{QoL})$ patients with advanced cancer ${ }^{(14)}$. In terms of general health condition, mean levels of $\mathrm{Hb}$ were tended to be anemic in both groups. Anemia is known for reducing the life quality of cancer patients through fatigue and a worse prognosis ${ }^{(15,16)}$. Poor conditions were also seen in terms of albumin, where $42 \%$ and $50 \%$ of MBD patients with and without pathological fracture, respectively, had hypoalbuminemia. Hypoalbuminemia is a poor prognosis because of decreased QoL, decreased response to therapy, and shortened survival rates of cancer patients ${ }^{(17)}$. In terms of calcium level, a normal mean was obtained from both groups. However, there were a few samples with hypercalcemia and hypocalcemia. Hypercalcemia can worsen the patient's condition through the osteoclastic bone resorption that occurs $^{(18)}$, so that it decreases bone density and can lead to pain. Hypocalcemia should be rare and is usually associated with kidney failure and administration of bisphosphonate therapy in cases of MBD. Complications that may occur in severe hypocalcemia are seizures and arrhythmias ${ }^{(19)}$.

There was no statistically significant difference in pain experienced by MBD patients with pathological fractures and MBD patients without pathological fracture. This can occur because pain is common in patients with advanced cancer, which is about $68 \%$ of cancer patients and $60-84 \%$ in cancer with $\mathrm{MBD}^{(6)}$. Another factor that can affect pain is therapy. Therapy in the form of osteoclast inhibitors can reduce pain ${ }^{(2)}$. In a systematic review published by van den Beuken-van Everdingen et al., the group that is given curative treatment shown a lower percentage of pain in cancer patients, which is $39.3 \%$, compared with $66.4 \%$ in advanced, metastatic, or terminal disease group ${ }^{(20)}$. Another thing to note is that the patients being observed had never felt extreme pain, so the VAS of 8,9 , and 10 could not be assessed ${ }^{(21)}$. In this study, the VAS found in breast MBD with pathological fractures was higher than those without pathological fracture. This could be associated with bone resorption mediated by osteoclast that often causes pain ${ }^{(8)}$. Lymphoma metastases (in this study all of them are Non-Hodgkin Lymphoma (NHL)) are MBD with the second-highest VAS, which is also associated with osteolytic lesions, especially in $\mathrm{NHL}^{(2)}$. The spine is the location of MBD with the highest mean of pain scale in the group with pathological fractures which could be related to complications of spinal cord compression which causes severe pain, impaired walking, and others ${ }^{(6)}$.

The absence of a statistically significant difference in hemoglobin levels in both groups is caused by various factors. The hemoglobin levels in MBD patients are found to be affected by its primary tumor and its 
disease progress ${ }^{(22,16)}$. Bone metastases occur mostly in axial bones, such as spines, ribs, and pelvis which are also active with hematopoiesis ${ }^{(2)}$, so we opine that the sites of pathological fractures may also be important, however, further study is needed. This study showed hemoglobin levels in the spine, pelvis, and femoral bone MBD were found to be lower in the group with pathological fractures compared to the group without pathological fracture, indicating that MBD with pathological fractures, especially in axial bones, probably has more serious hematopoiesis dysfunction. Therapy that is being/has been given to the patients also affected the hemoglobin levels. Cancer patients who are receiving chemotherapy have decreased hemoglobin levels from $<10 \mathrm{~g} / \mathrm{dl}$ to $<9 \mathrm{~g} / \mathrm{dl}$ starting from the $3 \mathrm{rd} \mathrm{week}^{(22)}$.

There was also no significant difference in albumin levels between MBD patients with pathological fractures and MBD patients without pathological fracture. However, albumin levels in pathological fractures group were slightly higher. This could be caused by the fact that serum albumin is a systemic response. The interpretation of albumin is also influenced by nutrition, the course of the disease, and the patient's hydration status ${ }^{(17)}$. Low albumin is often found in advanced cancer, and albumin levels can also be used to determine the prognosis and survival of cancer patients ${ }^{(23)}$. Primary tumors in the lungs were malignancies with the lowest albumin levels in the present study. Low albumin shows a poor prognosis in all malignancies, especially in lung cancer $^{(17)}$. The minimum level of albumin in MBD with pathological fractures is lower with levels ranging from 2.9-4.7 $\mathrm{g} / \mathrm{dL}$, while the percentage of hypoalbuminemia is higher in MBD without pathological fracture. Malnutrition and inflammation in cancer patients suppresses albumin synthesis through cytokine release, such as interleukin-6 (IL-6) which modulates albumin production in hepatocytes ${ }^{(17)}$. IL-6, along with other cytokines, are also known as cytokines that mediate osteoclast activation which then resorb the bone so that pathological fractures $\operatorname{occur}^{(7)}$.

In this study, no statistically significant difference also found between calcium levels in both MBD groups. In terms of data distribution, calcium in MBD with pathological fractures was wider, ranging from 7.6 to $12.6 \mathrm{mg} / \mathrm{dL}$ compared to MBD without pathological fractures. The mean of calcium levels in the group with pathological fractures was slightly lower, which may be influenced by a history of drug administration such as bisphosphonates and denosumab which are two of the therapeutic modalities expected to prevent future pathological fracture events ${ }^{(13)}$. The type of primary tumor can also affect, with lung cancer being the most common malignancy with hypercalcemia. Hypercalcemia can be related to the process of destruction of bone at an advanced stage and can lead to the incidence of pathological fractures that also cause pain ${ }^{(18,12)}$. In this study, all patients with hypercalcemia came with pain as the only/one of the chief complaints.

In the variable of non-medical treatment history, there was no significant difference between MBD with pathological fractures and MBD without pathological fracture. Of the 10 samples with a history of non-medical treatment, $6(60 \%)$ had pathological fractures. In this study, only 12 out of $64(18.75 \%)$ samples whose nonmedical treatment history were known. In a study conducted by Sprague et al., it was found that $55 \%$ of patients did not inform or discuss their alternative medicine with an orthopedic doctors ${ }^{(24)}$. The type of non-medical treatment chosen can determine the clinical condition of the patient. Treatments with acupuncture with drugs, Chinese herbal medicines, and reflexology were found to have benefits in cancer pain ${ }^{(25)}$. However, massage therapy showed small risks ${ }^{(26)}$. In Indonesia itself, the procedures performed in massage therapy also vary, where one traditional treatments have used antibiotics and collaborated with health workers and hospitals where some others still do not even prioritize sanitation ${ }^{(27)}$.

This research certainly has its limitations. First, in this study, we did not classify MBD patients by sex, age, underlying primary tumors, or other characteristics. Thus, different results can be obtained through study that classify MBD patients in certain groups before comparison. Second, this is a retrospective study using medical record data, so that the data used in this study is only based on the medical records obtained. Therefore, data such as the history of therapy and treatment that have been or are being undertaken by patients, which should be able to make the discussion in this study more comprehensive, cannot be investigated further. This study also did not classify MBD accompanied by the metastasis of other organs, which can cause different clinical conditions. Therefore, a similar study with a larger number of samples is needed to confirm the results obtained in this study in the future.

\section{CONCLUSION}

There was no statistically significant difference in clinical features of MBD patients, which is compared by VAS, laboratory findings: hemoglobin, albumin, and calcium, and history of non-medical treatment. The clinical condition in these MBD patients was found to be equally bad, especially in terms of pain, while those with fractures had worse conditions. Further studies with larger samples are needed to confirm the results of this study. 


\section{REFERENCES}

1. Manabe J, Kawaguchi N, Matsumoto S, Tanizawa T. Surgical treatment of bone metastasis: Indications and outcomes. Int J Clin Oncol. 2005;10(2):103-11.

2. Macedo F, Ladeira K, Pinho F, Saraiva N, Bonito N, Pinto L, et al. Bone metastases: An overview. Oncol Rev. 2017;11(1):43-9.

3. Saad F, Lipton A, Cook R, Chen YM, Smith M, Coleman R. Pathologic fractures correlate with reduced survival in patients with malignant bone disease. Cancer. 2007;110(8):1860-7.

4. Jauhari AH, Utami MS, Padmawati RS. Motivasi dan Kepercayaan Pasien untuk Berobat ke Sinse. Ber Kedokt Masy. 2008;24(1):1-7.

5. Singh VA, Haseeb A, Alkubaisi AAHA. Incidence and outcome of bone metastatic disease at University Malaya Medical Centre. Singapore Med J. 2014;55(10):539-46.

6. Tsuzuki S, Park SH, Eber MR, Peters CM, Shiozawa Y. Skeletal complications in cancer patients with bone metastases. Int J Urol. 2016;23(10):825-32.

7. Berenson J, Rajdev L, Broder Mi. Pathophysiology of bone metastases. Cancer Biol Ther. 2006;5(9):107881.

8. Vieira C, Fragoso M, Pereira D, Medeiros R. Pain prevalence and treatment in patients with metastatic bone disease. Oncol Lett. 2019;17:3362-70.

9. Wisanuyotin T, Sirichativapee W, Sumnanoont C, Paholpak P, Laupattarakasem P, Sukhonthamarn K, et al. Prognostic and risk factors in patients with metastatic bone disease of an upper extremity. J Bone Oncol [Internet]. 2018;13(September):71-5. Available from: https://doi.org/10.1016/j.jbo.2018.09.007

10. Chung LH, Wu PK, Chen CF, Weng HK, Chen TH, Chen WM. Pathological fractures in predicting clinical outcomes for patients with osteosarcoma. BMC Musculoskelet Disord [Internet]. 2016;17(1):1-8. Available from: http://dx.doi.org/10.1186/s12891-016-1351-x

11. Koo MM, Hamilton W, Walter FM, Rubin GP, Lyratzopoulos G. Symptom Signatures and Diagnostic Timeliness in Cancer Patients: A Review of Current Evidence. Neoplasia (United States) [Internet]. 2018;20(2):165-74. Available from: https://doi.org/10.1016/j.neo.2017.11.005

12. Coleman R. Metastatic bone disease: clinical features, pathophysiology and treatment strategies. Cancer Treat Rev. 2001;27(1):165-76.

13. Kimura T. Multidisciplinary approach for bone metastasis: A review. Cancers (Basel). 2018;10(6):1-10.

14. Mantyh P. The science behind metastatic bone pain. Eur J Cancer, Suppl. 2006;4(8):4-8.

15. Stasi R, Abriani L, Beccaglia P, Terzoli E, Amadori S. Cancer-Related Fatigue: Evolving Concepts in Evaluation and Treatment. Cancer. 2003;98(9):1786-801.

16. Caro JJ, Salas M, Ward A, Goss G. Anemia as an independent prognostic factor for survival in patients with cancer. Cancer. 2001;91(12):2214-21.

17. Gupta D, Lis CG. Pretreatment serum albumin as a predictor of cancer survival: A systematic review of the epidemiological literature. Nutr J [Internet]. 2010;9(1):69. Available from: http://www.nutritionj.com/content/9/1/69

18. Clines GA, Guise TA. Hypercalcaemia of malignancy and basic research on mechanisms responsible for osteolytic and osteoblastic metastasis to bone. Endocr Relat Cancer. 2005;12(3):549-83.

19. Diniotis B, Sternberg E, Shakuntala S, Chiha M, Khosla P. Hypocalcemia in Malignancy - Unexpected but Common. Cureus. 2015;7(12):10-3.

20. Van Den Beuken-Van Everdingen MHJ, Hochstenbach LMJ, Joosten EAJ, Tjan-Heijnen VCG, Janssen DJA. Update on Prevalence of Pain in Patients with Cancer: Systematic Review and Meta-Analysis. J Pain Symptom Manage [Internet]. 2016;51(6):1070-1090.e9. Available from: http://dx.doi.org/10.1016/j.jpainsymman.2015.12.340

21. Solomon L, Warwick D, Nayagam S. Apley's System of Orthopaedics and Fractures. Ninth. Hodder Arnold; 2010.

22. Pirker R, Pirolli M, Quigley J, Hulnick S, Legg J, Collins H, et al. Hemoglobin decline in cancer patients receiving chemotherapy without an erythropoiesis-stimulating agent. Support Care Cancer. 2013;21(4):987-92.

23. Viganó A, Bruera E, Jhangri GS, Newman SC, Fields AL, Suarez-Almazor ME. Clinical survival predictors in patients with advanced cancer. Arch Intern Med. 2002;160(6):861-8.

24. Sprague S, Lutz K, Bryant D, Farrokhyar F, Zlowodzki M, Bhandari M. Complementary and alternative medicine use in patients with fractures. Clin Orthop Relat Res. 2007;(463):173-8.

25. Bao Y, Kong X, Yang L, Liu R, Shi Z, Li W, et al. Complementary and alternative medicine for cancer pain: An overview of systematic reviews. Evidence-based Complement Altern Med. 2014;2014.

26. Yin P, Gao N, Wu J, Litscher G, Xu S. Adverse events of massage therapy in pain-related conditions: A systematic review. Evidence-based Complement Altern Med. 2014;2014. 
27. Notosiswoyo M, Suprapto A, Umboh J., Thah RA. Review of Research on Traditional Treatment of Fractures (Review Penelitian Pengobatan Tradisional Patah Tulang). Media Litbang Kesehatan. 2001;11(4):17-24. 